folge veränderter Selektionsverhältnisse mehr mutierte Keimkellen zur Befruchtung kommen als bei isolierter Hodenbestrahlung, ober ob die wahre Mutationsrate der Keimzellen durch die Mitbestrahlung des ganzen Somas erhöht wird - sei es durch eine Sensibilisie- rung gegenüber der direkten mutagenen Strahlenwirkung, sei es durch eine Hemmung von Erholungsprozessen, die im prämutativen Stadium eingreifen können, oder sei es schließlich durch Freisetzung oder Erzeugung eines mutagenen Agens.

\section{The pollen tube growth of Corchorus siliquosus L. as affected by MH and 2.4-D.}

\section{By R. M. Datta and B. S. Panda}

Department of Agriculture, Calcutta University, Calcutta-19 (Z. Naturforschg. 19 b, 543-544 [1964] ; eingegangen am 7. Januar 1964)

LEOPOLD ${ }^{1}$ writes that 1.2-dihydropyridamine 3-6dione (maleic hydrazide or $\mathrm{MH}$ ) was reported as a growth inhibitor with the remarkable properly of retarding overall plant growth without causing epinastic or other obvious morphological abnormalities.

2.4-Dichlorophenoxyacetic acid (2.4-D) is a herbicide and a growth regulator (ARnon and MACHLis) ${ }^{2}$.

Effects of growth substances, vitamins, chemicals, antibiotics and carotenoids etc. were added, besides sugar and boric acid, to observe the behaviour of pollen tube growth. In many plants these additions promote pollen germination and tube growth. In certain other cases, these substances do not produce a marked effect $\left(\mathrm{V}_{\text {ASIL }}{ }^{3}\right.$; Rietsema ${ }^{4}$ ), Chandler ${ }^{5}$ observed that pollen which did not germinate on a control medium and appeared non-viable, germinated satisfactorily with the addition of gibberellic acid (G.A.). She presumed that, due to the stimulating effect of G.A., it might be possible to "overcome some of the physiological incompatibilities characteristic of certain clones of these species". Numerous citations were recently reviewed by JoHri and $\mathrm{V}_{\mathrm{ASIL}}{ }^{6}$. In interspecific crossings of different jute species, it was observed by PAtel and DAtTA $^{8}$ that there was some sort of hindrance in accomplishing successful hybridization between different wild and cultivated species of jute. In order to overcome interspecific incompatibility in case of crossing it with other jute species, this preliminary study on a natural polyploid jute species (C. siliquosus) was undertaken to observe effects of these chemicals on pollen tube behaviour.

1 A. C. Leopold, Auxins and Plant Growth, University of California Press. Berkeley, U.S.A., p. 172 [1955].

2 D. I. Arnon and L. Machlis, Annual Review of Plant Physiology 4, 253 [1953].

3 I. K. VasiL, The cultivation of excised anthers and the culture and storage of pollen grains. $\mathrm{Ph}$. D. Thesis. Delhi University, India [1958].

4 J. Rietsema, Control of fertilization and embryo development. (In Maheswari, P. [Ed.]. Manual of Angiosperm embryology, Ronald Press, U.S.A. [1961].)

\section{Material and methods}

Im 1960 pollen tube growth of $C$. siliquosus was recorded following treatments with $\mathrm{MH}$ and 2.4-D in different concentrations along with culture media as detailed below. The range of room temperature was observed during the experimental periods as 28.0 to $30.5{ }^{\circ} \mathrm{C}$.

On December 5, 10 and 11, 1960 one drop of $8 \%$ Lactose gelatin-agar (hereinafter referred to as L.g.a.) and one drop of different concentrations of MH (.001, $.01,0.1,1.0$ and $10.0 \mathrm{ppm}$.) were placed on clean micro-cover glasses, mixed properly and then uniformly smeared.

On December 3, 5 and 16, 1960 one drop of $8 \%$ L.g.a. and one drop of different concentrations of 2.4-D $(1.0,3.0,5.0,7.0$ and $10.0 \mathrm{ppm}$.) were placed on clean micro-cover glasses, mixed properly and then uniformly smeared.

On December 5, 10 and 11, 1960 one drop of $4 \%$ sucrose gelatin agar (hereinafter referred to as S.g.a.) and one drop of $\mathrm{MH}(0.1 \mathrm{ppm}$. concentration) were placed on a clean micro-cover glass, mixed properly and uniformly smeared. Pollen in all these cases were dusted uniformly on micro-cover glasses coated with culture medium and desired concentrations of these chemicals.

In order to prepare a humid chamber of high intensity, a thick paper was cut to the size of the microcover glass taken and the middle portion was grooved and taken out leaving a narrow strip of paper measuring $1.5-2.0 \mathrm{~m} . \mathrm{m}$. in width. Then it was pasted over a glass slide and allowed to dry. A few small drops of distilled water were smeared on the hollow space of slide and the micro-cover glass dusted with pollen was inverted just over the thick paper frame and pressed down gently to make it air tight. A few minutes later water droplets in the form of dew appeared on the lower side of micro-cover glass, indicating high amount of humidity inside. Adoption of this technique gave bet-

5 C. Chandler, The effect of gibberellic acid on germination and pollen tube growth. Contr. Boyce Thomp. Inst. 19, 215 [1957].

6 B. M. Johri and I. K. VAsil, Physiology of pollen. Bot. Rev. 27 (3), 325 [1961].

7 G. I. Patel and R. M. Datta, Interspecific hybridization between Corchorus olitorius Linn. and C. capsularis Linn. and the cytogenetical basis of incompatibility between them. Euphytica. 9 (1), 39 [1960].

8 R. M. Datta and P. K. Biswas (in press). Effects of auxins and anti-auxins on the rate of pollen tube growth of Crotalaria juncea. 
ter pollen tube growth than keeping such slides on glass rods under bigger petri-dishes with a few drops of water.

The growth of the pollen tube was measured on the basis of 3 days' observations in all cases.

\section{Results}

Pollen grown on $8 \%$ L.g.a. medium had a mean pollen tube length of 533 microns (Table I). Pollen dusted on $8 \%$ L.g.a. +0.001 and 0.01 ppm. MH respectively did not germinate at all, while pollen dusted on $8 \%$ L.g.a. $+10.0 \mathrm{ppm}$. MH burst out in majority, thus preventing further observation. Pollen grown on $4 \%$ S.g.a. had a mean pollen tube length of 225 microns. Pollen grown of $4 \%$ S.g.a. $+0.1 \mathrm{ppm}$. $\mathrm{MH}$ had a mean length of 609 microns.

Pollen grown of $8 \%$ L.g.a. +1.0 ppm. 2.4-D grew but as they were a few in number, measurements could not be taken fully. Pollen grown on $8 \%$ L.g.a. +3.0 ppm. 2.4-D had a mean pollen tube length of $474 \mathrm{mi}-$ crons. Pollen grown on $8 \%$ L.g.a. +5.0 ppm. 2.4-D had a mean pollen tube length of 511 microns. Pollen grown on $8 \%$ L.g.a. $+7.0 \mathrm{ppm}$. 2.4-D had a mean pollen tube length of 537 microns. Pollen grown on $8 \%$ L.g.a. +10.0 ppm. 2.4-D had a mean pollen tube length of 257 microns.

Bursting of pollen was lower in control in comparison to those with different concentrations of these chemicals. In case of pollen grown on $8 \%$ L.g.a. +10.0 ppm. 2.4-D in particular, there was an abnormal bursting as well as pollen tubes of varying lengths. Hence a record was kept in regard to the number of pollen burst, number of pollen tubes burst and number of pollen tubes unburst and their percentages were calculated individually and tabulated as follows: $-\%$ of pollen burst $-45.42 ; \%$ of pollen tubes burst -37.46 and $\%$ of pollen tubes unburst -16.51 .

While nothing conspicuous had been marked in the shape and size of pollen tubes grown on $8 \%$ L.g.a. or
4\% S.g.a. in combination with $\mathrm{MH}$ or 2.4-D concentrations, unusual slenderness and concentration of varying degrees in pollen tubes were noted in all cases.

\section{Discussion}

MH is regarded as a growth inhibitor but this increased pollen-tube growth on s.g.a. but seemed to decrease growth on l.g.a. 2.4-D is a growth regulator but five ppm. and less 2.4-D did not affect length of pollen tube. Seven ppm. of this chemical increased a little but in ten ppm. decreased length resulted. Pollen tube length on $8 \%$ l.g.a. was double that on $4 \%$ s.g.a. Auxins, anti-auxins, different chemicals and sugars etc. affect differently with different plant species in their pollen tube growth (Rietsema) ${ }^{7}$. So, anti-auxin, it appears, acts differently. As $\mathrm{MH}$ has increased the pollen tube measurement in this plant, its different concentrations should be tried to observe their effects along with other anti-auxins in different doses though this chemical has been found to show retarding effcets in the pollen tube growth of Crotalaria juncea (Datta and Biswas, in press).

In the end, we wish to thank our esteemed friend Dr. S. C. Darta of Botany Department, Calcutta University for kindly going through the Botany Department, Calcutta University
manuscript and suggesting improvements.

\begin{tabular}{|l|l|}
\hline \multicolumn{1}{|c|}{$\begin{array}{c}\text { Treatments } \\
{[\%]}\end{array}$} & $\begin{array}{c}\text { Growth } \\
\text { in microns }\end{array}$ \\
\hline 1. 4 S.g.a. (Control). & $224 \pm 47$ \\
2. 4 S.g.a. + $0.1 \mathrm{ppm} . \mathrm{MH}$ & $609 \pm 106$ \\
3. 8 L.g.a. (Control). & $533 \pm 120$ \\
4. 8 L.g.a. $+0.1 \mathrm{ppm}$. MH & $383 \pm 113$ \\
5. 8 L.g.a. $+1.0 \mathrm{ppm}$. MH & $368 \pm 119$ \\
6. 8 L.g.a. $+3.0 \mathrm{ppm}$. 2.4-D & $474 \pm 116$ \\
7. 8 L.g.a. $+5.0 \mathrm{ppm} .2 .4-\mathrm{D}$ & $511 \pm 117$ \\
8. 8 L.g.a. $+7.0 \mathrm{ppm} .2 .4-\mathrm{D}$ & $537 \pm 128$ \\
9. 8 L.g.a. $+10.0 \mathrm{ppm} .2 .4-\mathrm{D}$ & $257 \pm 69$ \\
\hline
\end{tabular}

Table 1. Relation between pollen tube growth and various treatments of $\mathrm{MH}$ and 2.4-D (4 hours in all cases). 